\title{
PENTAZOCINE ABUSE IN SICKLE CELL ANAEMIA PATIENTS: A REPORT OF TWO CASE VIGNETTES
}

\author{
Alfred B. Makanjuola*1 Philip O. Olatunji ${ }^{2}$ \\ ${ }^{1}$ Department of Behavioural Sciences, University of \\ Ilorin Teaching Hospital, Ilorin, Nigeria \\ ${ }^{2}$ Department of Haematology, University of Ilorin Teaching Hospital, Ilorin, Nigeria
}

\begin{abstract}
The article aims to draw attention of clinicians to the addictive potentials of Pentazocine use in sickle cell anaemia patients and to highlight some of the associated problems of pentazocine abuse. It also hopes to stimulate the need to review guidelines for the use of analgesics in the management of bone pain crisis or other chronic pains. Two case reports of pentazocine abuse seen in a psychiatry clinic at the University of Ilorin Teaching Hospital (UITH) Ilorin, Nigeria were made. It was found that both patients who were sickle cell anaemia $(\mathrm{HbS})$ patients were first given intramuscular pentazocine in private hospitals during an episode of bone pain crises. They claimed that though the bone pain crises subsided after a few days on admission, they continued to feign pains in order to be given pentazocine because they enjoyed its dysphoric effect. There were features of pentazocine dependence as shown by intense craving for the drug, excessive sweating, body (not bone) pains, signs of needle pricks on the body, sudden extravagance, begging for money, stealing and poor academic performance among other things. There was no clinical evidence of bone crisis or complications of sickle cell anaemia. It was concluded that more than before, clinicians should be cautious in the use of analgesics which has potential for addiction in sickle cell anaemia and chronic pain patients.
\end{abstract}

KEY WORDS: Pentazocine abuse; Sickle cell anaemia, Nigeria

\section{INTRODUCTION}

In Nigeria, Pentazocine is commonly used in the management of surgical and chronic pains. It is especially used in the management of bone pain crisis of sickle cell anaemia. Pentazocine is a narcotic agonist/antagonist analgesic derived from benzmorphinan.
It is an opioid drug developed in 1967 as a result of efforts to find an effective but less dependence-producing analgesic when compared with morphine. It produces little or no euphoria but has some dysphoric effect in a few individuals (Lang \& Pilon, ). It was initially thought to be non-addictive, but its potential for abuse was soon realized (Weber \&

Corresponding author: Dr A.B Makanjuola*, Consultant Psychiatrist, University of Ilorin Teaching Hospital, Ilorin, Nigeria.E-mail: makanju2@yahoo.com 
Fromme, 1970; Huskisson, 1974). Since then, various efforts have been made to reduce its abuse including the production of a brand that contains enough antagonist (naloxone) to counteract its effect, if the tablet is dissolved and injected. An example of this brand is Talwin Nx. Other efforts include the classification of Pentazocine as a controlled drug in some countries such as United States of America where it is classified under Schedule IV in the Controlled Substances Act.

The earliest data on substance use and abuse in Nigeria emanated in the 1960s, and were hospital based (Asuni, 1964; Lambo, 1965). Thus, Lambo in 1965 reported 18 cases of cannabis abuse out of 4000 patients seen in Neuropsychiatric Hospital, Abeokuta, Nigeria. Also, Asuni in 1964 reported cannabis abuse in 13 out of 380 patients discharged from Neuropsychiatric Hospital, Yaba, Lagos, Nigeria. Since then, there had been reports on substance use and abuse in Nigeria. While some were hospital based (Adelekan \& Adeniran, 1988; Ohaeri \& Odejide, 1991), others were community based (Anumonye, 1980; Onibokun et al, 1999). Some studies have focused on atrisk groups such as secondary school students (Adelekan, 1989; Adelekan et al, 2001), undergraduates (Frank \& Edward, 1999; Adelekan et al, 2000) health workers (McAuliffe \& Rohman, 1986). As a result of these studies, various drugs of abuse such as alcohol, tobacco, cannabis, stimulants, cocaine, heroin, hallucinogens e.t.c. have been documented. The frequency of use of some of these drugs tends to vary depending on, among other factors, their availability, accessibility and effectiveness of legislation against them. However, in Nigeria and most especially in the area of study, no documented report exists on the abuse of Pentazocine especially among sickle cell anaemia patients. This report therefore is aimed at highlighting the addictive potential (and its associated problems) of Pentazocine use as an analgesic in patients with sickle cell anaemia and secondly to stimulate the need for review of guidelines for the use of analgesics in the management of bone pain crisis or other chronic pains.

\section{METHOD}

A report of two cases of pentazocine abuse seen in a psychiatry outpatient clinic in the University of Ilorin Teaching Hospital, Ilorin, Nigeria.

\section{Case Reports}

Case one: Miss X is a 23-year-old Nigerian undergraduate with sickle cell anaemia whose electrophoretic pattern was $\mathrm{HbS}$. She presented on the $8^{\text {th }}$ of June 2004 with one-year history of self-injection with Pentazocine. This started following her previous admission into a private hospital in Lagos on account of bone pain crisis. She claimed the pains was localized mainly in the chest, hands and thighs. While on admission, she was treated with DF 118 , one tablet thrice daily, tramadol, one tablet when necessary and intramuscular pentazocine $30 \mathrm{mg}$ once daily. Patient claimed though she was on pentazocine for about 45 days, she actually had bone pains only in the first one week of admission. She thereafter started feigning pain in order to be given pentazocine as she enjoyed its euphoric effect. After discharge, she started self-administering pentazocine. The most preferred site of self-injection was her thighs so that it could be hidden from her siblings and colleagues. While in school, she often sneaked into the emergency room of a nearby Teaching Hospital, picked up some prescription sheets (without permission), prescribed Pentazocine using forged signatures and procured it from different pharmaceutical shops. Sometimes she bought Pentazocine without prescription, as the pharmacy attendants had known her over time. She spent about six hundred Naira (about \$4.00) per day on Pentazocine alone. She sourced money by taking loans from friends, exploiting her mother, and from strangers. Though she claimed she does not prostitute to get money for drugs, her younger sister claimed, on many occasions she had left the campus on trips with men. In the past eight months, patient claimed she was using Pentazocine on daily basis. Delay in procuring it causes running nose, severe 
body pains, restlessness, insomnia and intense craving for the drug. Each injected intramuscular dose of $30 \mathrm{mg}$ lasts for about five hours. She claimed that the need for the drug has taken a primacy effect over other activities. Usually, her first dose for the day would be taken first thing in the morning while the second dose would be taken just before bedtime. In spite of her awareness that she was already dependent, she could not voluntarily stop. The patient's inability to voluntarily stop the drug and her inability to keep up with the cost of the needed doses per day prompted her to intimate a friend of her problems. She was taken to a medical Consultant/Clergyman who then referred her to a Consultant Heamatologist (P.O). The Haematologist assessed her and referred to a Psychiatrist (A.B). The two Units thereafter, co-managed the patient.

On mental state examination, patient was well kempt, co-operative and appeared well motivated. She had rhinorrhea and was a bit restless. She claimed she was feeling cold and feverish in spite of the hot weather. She had no hallucinatory experiences or behaviour suggestive of such. There was no abnormality of stream, form, content and possession of speech. Her cognitive functions were within normal limits. She had a full insight. On physical examination, patient was slightly small for age, mildly icteric and had a slightly protruding abdomen. She had goose pimples and multiple hyperpigmented macules on the anterior aspects of both thighs (from needle pricks).

A diagnosis of Pentazocine dependence was made and patient was admitted on to the medical ward for detoxification as the Teaching Hospital, as at the time of this report, did not have a separate drug ward apart from the psychiatric ward. While on the ward, she was placed on oral Chlorpromazine 100mg b.d and oral Benzhexol 2.5mg b.d. In spite of the vigilance by nurses and relatives, patient on several occasions still self-injected and purchased Pentazocine by sending unsuspecting relations of newly admitted patients to purchase the drug for her. She often lied to them, claiming that she had been given an emergency prescription and her relations had not turned up to buy the drug for her. In view of these tricks, patient was transferred to the psychiatric ward a week from the date of admission. On the psychiatry ward, she was monitored more closely and a chart detailing her movement at all times was kept. She was not allowed access to writing materials and money. She was discharged after 23 days having satisfied some set goals such as presumed elimination of drug in the system, improved health and physical functioning and, reduction in potential hazard to public health and safety. This was based on patient's response at clinical interview sessions, counseling sessions and report from her confidant and closest relatives around (her younger sister). The Chlorpromazine and Benzhexol tablets were tapered off after two weeks post discharge.

Case Two: Mr Y is a 25-year-old University drop-out with sickle cell anaemia with $\mathrm{HbS}$ electrophoretic pattern. He is the last of three children all with sickle cell anaemia. The first is a male and a medical doctor who died about two years ago, while the second is a female who, patient claims, abuses Pentazocine also. Mother is a petty trader while father is a retired middle level civil servant. Patient was first seen on the $10^{\text {th }}$ of February 2005 on account of four-year history of self-injecting with Pentazocine. Though patient had been given Pentazocine on a few occasions while on admission at the University of Ilorin Teaching Hospital, he became addicted to the drug about four years ago when he was admitted at a private hospital in Lagos on account of osteomyelitis of the left mandible. While on admission, he claimed, he was given intramuscular Fortwin (Pentazocine) 30mg b.d and parenteral antibiotics for about 3 weeks. Thereafter, patient claimed, he continued to feign pain in the jaw and the thigh so that he could continue to be given Pentazocine as he enjoyed the 'euphoric experience' the drug gave him. After discharge, patient presented at the Accident and Emergency Unit of University of Ilorin Teaching Hospital, Ilorin feigning bone pain crisis. He specifically requested the attending doctor to prescribe intramuscular Pentazocine, folic acid and chloroquine tablets. Patient's access to doctors was facilitated because most of 
them knew his late brother as a colleague. This facilitated his chance of being given a prescription without entering it into his case notes. This allowed him to have multiple prescriptions within a short period of time without the doctors' knowledge. At a point, some doctors became suspicious of his incessant complaints and would ask him to present at the sickle cell clinic. Thus, he started stealing prescription sheets and forging prescriptions. Most times, at the pharmacy stores, his prescription sheet will not be requested for or scrutinized as he was well known to the attendants.

Patient claimed he self injects once daily, which translates to about 300 Naira (\$2) per day. He sustains his drug habit through begging, especially from hospital workers and patients' relatives. He also goes to public places with fake prescription sheet to beg for money and sometimes makes up to 200 to 500 Naira daily. He often stole and sold items from the house to make money. His persistent begging for money has made him a common feature on the corridors of the hospital until he was referred to the Psychiatrist for management. Patient expressed a wish to be treated for drug abuse (Pentazocine). He admitted that the drug behaviour had made him an object of ridicule at home and in the community. His academic records had also been negatively affected. He claimed he knew he was being ruined gradually by the drug yet he could not stop. He therefore readily accepted to being managed on the psychiatry ward.

On mental state examination, patient was poorly kept, co-operative and appeared quite motivated. He was apprehensive but not restless. He had no rhinorrhea or feverish feelings. Other aspects of mental state examination were essentially normal. On physical examination, he was markedly small for age and mildly jaundiced. He had multiple hyperpigmented macules (needle prick points) on the anterior and medial aspects of the cubital regions of both upper limbs. A diagnosis of Pentazocine dependence was made and patient was to be co-managed by the Psychiatry and Haematology Units. Since there was no drug ward, patient was detoxified on the psychiatry ward using oral Chlorpromazine $100 \mathrm{~m}$ b.d. and oral Benzhexol $2.5 \mathrm{mg}$ b.d. Patient was discharged after three weeks having satisfied some set goals such as presumed elimination of drug in the system, improved health, reduction in potential hazard to public health and safety. This was based on patient's responses at clinical interview sessions, counseling sessions and report from relations and ward staff. He was referred to the outpatient clinic for continuation of counseling, rehabilitation and maintenance of drug free behaviour.

\section{DISCUSSION}

Report of incidence and features of Pentazocine abuse in our environment has not been given enough priority. Authors in other parts of the world had reported some features of ulcers that could indicate the use of pentazocine (Ghandi et al, 2004; Prasad et al, 2004). Based on the two cases presented, we suggest that, in a sickle cell anaemia patients, the presence of one or a combination of needle prick points, an increase in frequency of report of 'bone pain crisis' (usually a feigned pain) and a sudden non-prudence on financial matters should raise a suspicion of parenteral drug abuse until otherwise proven.

In the above two case vignettes, they were both exposed to the use of Pentazocine, an opioid drug, subsequent to an episode of genuine need for the drug (bone pain crisis in the first case and oseomyelitis in the second case). It is worthy of note that the use of Pentazocine was prolonged (at least three weeks) in both cases. It was also observed that both cases continued to feign pain after genuine pain had subsided in order to continue to self-inject Pentazocine. At this point, it could be said that the patients were becoming addicted and needed the drug not for its pain relieving properties but for its euphoric effect. This will suggest a need for doctors taking care of patients with chronic pains to appreciate the difference between genuine and feigned pain. While this point may seem obvious, there is a need to caution that, to wrongly be on any side could be danger- 
ous. To wrongly assume a patient is feigning pain and therefore withhold potent analgesic is unethical and may unduly prolong suffering, whereas to assume the converse could as well predispose the patient into drug addiction. It is therefore pertinent for clinicians to set out formal guidelines or charts for determining when, how and what analgesic to give while attending to different categories of pain disorders. Such protocol/guideline would need to be reviewed until the best of practice is achieved.

The above cases also illustrate the accompanying dangers of drug dependence. On its own, the management of sickle cell anaemia may predispose a family to physical, psychosocial and financial stress. The presence of a co-morbidity of sickle cell anaemia and drug dependence might further affect their clinical and psychological states. The dependent patient continues to inject Pentazocine in order to alleviate or eliminate withdrawal symptoms. To sustain and fund the drug habit, he/ she may engage in antisocial behaviours such as stealing, begging, lying, prostitution especially in females, and selling properties at ridiculous prices. These behaviours were exhibited by the two cases cited above and could, if unchecked, further compromise their physical and mental health. There is therefore, a need to ensure careful use of analgesics with addictive potential in these patients in order to minimize societal cost of health.

The patients were to go through two phases of treatment; detoxification and stabilization phase and, the rehabilitation and relapse prevention phase. In the study centre, we could not detoxify patients using dose-tapered opioid agonists such as methadone nor partial antagonist such as buprenorphine or adrenergic agonist such as clonidine and lofedipine. In the alternative, and for calming effect the patients were placed on oral dose of chlorpromazine $100 \mathrm{mg}$ twice daily to be adjusted according to clinical response. The Chlorpromazine was tailed off two weeks after discharge.

In spite of the limitations of facilities for substance and drug abuse management in the treatment centre, the authors have within the available resources managed these cases of
Pentazocine abuse by dividing treatment into detoxification/stabilization and rehabilitation/ relapse prevention stages. While we could state that the patients had successfully gone through the detoxification/stabilization phase, plasma or urine pentazocine level monitoring would be needed to determine the degree of relapse prevention. Reports have shown that the proportion of patients using opioids (heroin) tend to drop from $17 \%$ to $6 \%$ after residential rehabilitation programmes (UNODC, 2002). We would have referred the patients to self-help groups but we could not, as such groups do not exist in this environment. However, the patients are still being followed up in the outpatient clinic on a monthly basis for abstinence-oriented counseling. The satisfactory and quick recovery in these patients so far seemed to be a reflection of their high level of motivation, absence of psychiatric symptoms, family support, intensive counseling and a relatively low severity of substance use (UNODC, 2002). These factors have been shown to improve recovery, treatment adherence and attitudinal change.

In conclusion, we suggest that seminars be organized for health workers on the use of pentazocine (and other analgesics) in sickle cell anaemia disease. Patients with chronic pain should also be counselled on the symptoms of dependence on analgesic drugs and to report same to their doctors immediately. Where not in existence, drug units (separate from the general psychiatric ward) should be established in all tertiary hospitals. Finally, legislation against indiscriminate sales of controlled drugs should be enforced.

\section{REFERENCES}

Adelekan, M.L. (1989). Self-reported drug use among secondary school students in Ogun State, Nigeria. Bulletin on Narcotics, 41,109-116.

Adelekan, M.L. and Adeniran, R.A. (1988). Psychosocial and clinical profile of hospital managed drug abusers in Nigeria. $\mathrm{Ni}$ gerian Medical Journal, 18, 461-568. 
Adelekan, M.L., Makanjuola, A. B., Ndom, R.J.E., Fayeye, J.O., Adegoke, A.A., Amusan O. and Idowu, A.I. (2001). 5-Yearly Monitoring of trends of substance use among secondary school students in Ilorin, Nigeria, 1988-1998. West African Journal of Medicine, 20, 28-36.

Adelekan, M.L., Ndom, R.J.E., Makanjuola, A.B., Parakoyi D.B and Osagbemi G.K,

Fagbemi O. and Petu A.O. (2000) Trends analyses of substance use among undergraduates of University of Ilorin, Nigeria, 1988-1998. African Journal of Drug and Alcohol Studies, 1, 39-52.

Anumonye, A. Drug use among young people in Lagos, Nigeria.(1980). Bulletin on Narcotics, 32, 39-45.

Asuni, T. (1964). Socio-psychiatric problems of drug abuse in Western Nigeria. African Journal of Psychiatry, 16, 17-28.

Frank, J.I. and Edward, M.A. (1999). A comparison of trends in drug use among students in the USA and Ontario, Canada: 1975-1997. Drug: Education, Prevention and Policy, 6, 17-27.

Ghandi, V., Agrawal, S.K., Chatterjee, A.K., Sachdava, B., and Bhattachaya, S.N. (2004). Pentazocine induced cutaneous sclerosis and panniculitis in an Indian male. International Journal of Dermatology, 43 (7), 516-7.

Huskisson E.C. (1974). Simple analgesic for arthritis. British Medical Journal, 4, 196.

Lambo, T.A. (1965). Medical and social problems of drug addiction in West Africa, with special emphasis on psychiatric aspects. Bulletin on Narcotics, 17, 3-13.
Lang D.W and Pilon R.N. ( 1980). Naloxone reversal of morphine-induced biliary colic. Anaesth. Analg, 59 (8), 619-20.

McAuliffe W.E, Rohman M., Santangelo S., Feldman B., Magnuson E., Sobol A \&

Weissman J. (1986). Psychoactive drug use among practicing physicians and medical students. New England Journal of Medicine, 25 ( 315), 805-810.

Ohaeri, J.U. and Odejide, A.O. (1991). Admissions for drug and alcohol-related problems in Nigerian psychiatric care facility in one year. Drug and Alcohol Dependence, 31, 101-109.

Onibokun, A.G., Adelekan M.L, Adeyemi A.A, Adeyemi B. Alade I, Apantaku S.O, Atoyebi A.O., Badejo I, Ibiyemi B, Makanjuola A.B, Ndom R.J.E. (1999). The drug nexus in Africa: A Technical Report submitted to United Nations Office for Drug Control and Crime Prevention. Vienna: United Nations Office for Drug Control and Crime.

Prasad H.R., Khaitan BK., Ramam M., Sharma VK., Pandhi RK., Agarwal S., Dhawan A., Jain R \& Singh MK, (2005). Diagnostic clinical features of pentazocine-induced ulcers. International Journal of Dermatology, 44 (11), 910-5.

United Nations Office on Drug and Crime (2002). Contemporary drug abuse treatment: a review of evidence base. Vienna: UNODC.

Weber W.F and Fromme H.P. Addiction to pentazocine; report of two cases (1970). JAMA., 212, 1708. 